\title{
Legal Societal System Intervention Trauma to Child Sexual Abuse Victims Following Disclosure in the Lusaka Urban District of Zambia
}

\author{
by \\ Anselimo Boniface Mbuzi and Mwiya L. Imasiku
}

\section{ABSTRACT}

The rigorous hospital, police and legal procedures through which sexually abused children go through can further increase the level of trauma if not done professionally. If these procedures are performed in a sensitive and knowledgeable manner this can lead to an expedited healing process for the child who is sexually traumatised. Trauma is not just a health hazard but a condition that can impair full disclosure of required details by a child who has been sexually abused.

In Phase 1, four in-depth case studies of children who were sexually abused were carried out using the qualitative method of one to one oral interviews. Phase II involved an investigation into the relationship between societal interventions such as court procedures and trauma levels in fifty sexually abused children. The tool that was used to assess or to measure the level of trauma and determine the amount of stress experienced by each child was the Trauma Symptoms Checklist for children. This instrument was developed by John Biere (1989). The data obtained was analysed using descriptive analysis.

The police officers, the social workers and health workers indicated that they had interviewed 50 per cent of the sexually abused children three times while the remaining 10 per cent reported to have been interviewed more than three times. It was further reported that each child had an average of three cross examinations in the courts of law. The Trauma Symptoms Check List revealed that twenty five (50\%) of sexually abused children who had been separated from their primary care-givers exhibited more stress and trauma than their counterparts. It was also found that fifteen of the sexually abused children who were taken to the juvenile courts of law exhibited less stress and trauma than their colleagues who were taken to the regular adult courts. It was also observed that 75 per cent of the sexually abused children who indicated that they had trusting relationships with the professionals expressed being at ease with them.

This study indicates that certain types of societal system interventions such as multiple questioning, more than three interviews, child-mother or care-giver separation, inadequate trust during the investigation, court procedures and social service phases, further traumatised sexually abused children.

Key words: Trauma, Societal Interventions, Sexual Abuse Disclosure. 


\section{INTRODUCTION}

\section{Background to the Study}

This study intended to explore if the investigatory processes, court proceedings, legal service interventions in intra family child sexual abuse cases increase the level of trauma experienced by child victims following disclosures. A conceptual framework of the background information pertaining to the legal societal factors that prevent full disclosure and instead induce additional trauma of child sexual abuse was discussed in terms of responses from various stakeholders such as magistrates, lawyers, policemen and child victims of sexual abuse and their caregivers. The chapter also presents the aim and objectives of the study. In this article, the term societal intervention is used to refer to the court strategies and procedures that a sexually abused child is subjected to. In different parts of this article, another term that has been taken to mean the same as trauma is the child's experience of distress. Situations which are too stressful for the child were thus used to refer to as additional trauma.

Research on child sexual abuse has a long history because abuse of children is a very old problem of mankind to an extent that its awareness has had cycles of discovery and suppression (National Guidelines for the Multi-disciplinary Management of Victims of Sexual and Gender Based Violence in Zambia, 2009). Although child sexual abuse in Zambia was previously perceived as a domestic case, it is now regarded as a violation of human rights and personal liberties that undermine good governance. To execute this paradigm shift, several societal systems or structures to address the problem of Child Sexual Abuse (CSA) have been put in place in Zambia (National Guidelines for the Multi-disciplinary Management of Victims of Sexual and Gender Based Violence in Zambia, 2009).

\section{Problem Statement}

Experts have argued that in child testimony, certain system interventions that are not child-friendly can be psychologically harmful to children (Berliner and Berbierie, 1984). This indicates that lack of knowledge and training in the people who stand in to support the child victims of abuse, instead of helping, end up harming the disclosure process and thereby exerting more traumas on the child who has been sexually abused and in turn thereby silencing the child (Sgroi, Blick and Porter, 1982). Clinical psychologists believe that psychological damage is caused not only by the abuse but by being forced to testify in an open court in the presence of the accused (Bjerrgaard, 1989). Understanding the dynamics affecting child victims of sexual abuse would thus encourage the process of disclosure. Tedesco and Schnell (1987), through their studies attested to the fact that an initial session between a child witness service providers and a child witness, gives an impression that a sexually abused child appears to be the same as any other child confronted with a stressful experience. However, the difference between the two aforementioned categories of children is that a sexually abused child in addition to the stress of unpleasant experience of abuse, violence 
or family conflict that she brings, there can be certain court procedures that induce additional distress or trauma in them. This experience which can impact negatively on the child's behaviour and perception of his/her environment has been labelled by the professional world as traumatic. Child witness role-players or the legal personnel, usually have no knowledge of this underlying trauma. According to Lewis (1999), this knowledge gap is not at all good because child witness role-players or legal personnel need to have a better understanding of the psychological hindrances which the societal system intervention can bring to the child witness in order to obtain full and accurate details from children who have been sexually abused. This is of crucial importance to the legal outcome of the investigative process because one reason why there might be so few cases of prosecution is that there is rarely any proper evidence available other than the child's fragmentary report which consequently may prevent the child from receiving a fair trial and outcome.

Therefore, it can be argued that a significant gap still remains between the vision of societal intervention procedures which endeavour to reduce stress and improve children's ability to give their best evidence and the reality of children's experiences. The study intended to find some of these missing pieces and also to partially attempt to answer why many cases of child sexual abuse end up as acquittal cases in favour of perpetrators in Zambia even if the sexual abuse did in reality take place. The study investigated and examined the experience of additional trauma the child has as a result of societal systems interventions.

\section{METHODOLOGY}

In order to collect data on societal system intervention trauma from key informants or gate keepers, an in-depth study approach which followed a descriptive research design was used. A total of fifty-four participants, girl children aged between nine and sixteen were included in the study. Four participants were engaged in Phase I case studies and fifty participants in Phase II. Both phases involved children reported to have been sexually abused and had come out in public and whose cases went through the police, hospital or clinics, courts of law in Lusaka. However, focus was more on those involved in court proceedings.

In Phase I, four in-depth case studies of children who were sexually abused were carried out using the qualitative method. Interviews were conducted with any other persons who were directly involved in any of the four cases of sexually abused children, for example, parents or guardians, friends, police officers, nurses at the hospital or clinic where the case(s) were reported, magistrates who presided over the case in the court and counsellors at the child protection centre, the Young Women Christian Association (YWCA). Data was obtained from case records at magistrates and High Courts, hospitals or clinic victim police units, counselling centres in order to validate what the interviewees had reported on child sexual abuse cases.

Phase II employed a proscriptive survey which involved an investigation into the relationship between societal interventions or court procedures and trauma levels in fifty sexually abused children. This phase involved administration of the Trauma 
Symptoms Checklist for children. It was assumed that their responses would help to determine the societal interventions which induced additional trauma in the children.

Prior to the main study, a pilot study was undertaken with four participants selected as per the inclusion criteria adapted for the main study. The pilot study was done in order to evaluate and finalise the choice of the tools to be used for the study and to determine the ease of administration of the tools and its relevance to the population under study.

\section{Assessment Tools}

Two testing instruments were administered during a semi-structured interview in order to measure the level of trauma and to determine the amount of societal system intervention stress experienced by each child. The Trauma Symptom Checklist for children (Briere, 1992) was administered to establish a trauma score for each child. Its purpose was to assess childhood trauma and especially sensitive to sexual abuse (Biere, 1992). However to measure the probable level of stress that the investigatory legal, and social service interventions produced, an interview schedule was developed by the researcher for the purpose of the study. Its purpose was to establish relative weights for the different experiences likely to be encountered by children in the process of intervention following report of child sexual abuse.

\section{RESULTS OF THE STUDY}

The results have been presented according to the following themes:

1. Multiple interview or multifaceted questioning.

2. Testifying in adult magistrate courts.

3. Removal or separated from mother or primary caregiver.

4. Trust between sexually abused children and professionals attending to them.

5. Credibility of child witness in regular adult courts.

Table 1: Corrections of Levels of Trauma and the Societal Interventions Strategies

\begin{tabular}{|c|c|c|c|}
\hline $\begin{array}{l}\text { Mean number of interviews } \\
\text { in all the societal } \\
\text { intervention phases }\end{array}$ & $\begin{array}{l}\text { Mode of Number } \\
\text { of Interviews }\end{array}$ & Percentage & $\begin{array}{l}\text { Correlation between No of } \\
\text { Interviews and trauma scores }\end{array}$ \\
\hline $\mathbf{3}$ & $\mathbf{4}$ & $\mathbf{6 1 \%}$ & P value 0.013 \\
\hline
\end{tabular}

Source: Field Data, 2012 


\section{The Level of Association Being 0.29}

\begin{tabular}{|c|l|l|}
\hline Serial No. & Factors Correlated to Trauma Symptoms & Correlation coefficient \\
\hline A & Multiple interviews & $.878^{* *}$ \\
\hline B & Testifying in adult magistrate courts & $.831^{* *}$ \\
\hline C & Testifying in juvenile courts & $0.071 \mathrm{NS}$ \\
\hline D & $\begin{array}{l}\text { Removal or being separated from primary } \\
\text { care-giver who is a perpetrator }\end{array}$ & $.061 \mathrm{NS}$ \\
\hline E & Being subjected to more than three (3) interviews & $.878^{* *}$ \\
\hline F & $\begin{array}{l}10 \% \text { of children subjected to less than three (3) } \\
\text { interviews }\end{array}$ & $0.081 \mathrm{NS}$ \\
\hline G & Multiple Questioning & $.813^{* *}$ \\
\hline
\end{tabular}

$\mathrm{P}<0.01$ Significant; $\mathrm{P}<0.05$, NS Not significant

Source: Field Data, 2012

\section{A. Multiple Interviews}

The mean number of investigatory interviews per child was three. The mode was four interviews with thirty children $(55 \%)$. Correlations were used to analyse the data for a number of interviews and trauma score. The correlation between the number of interviews and trauma scores yielded a P Value of .013 with the level of association being 0.29 which was significant.

Regarding multiple interviews, the present study revealed that being subjected to more than four interviews led to an experience of additional trauma in the child witnesses of sexual abuse $[\mathrm{P}$ value $=0.08, \mathrm{NS}]$

\section{B. Testifying in Adult Magistrate Courts}

During the legal intervention phase, thirty-four children testified in the juvenile court while twenty testified in the adult magistrate courts. The correlation between trauma and testifying in adult magistrate courts was 0.831 which is significant while that for juvenile courts was 0.071 which is not significant. The study revealed that children who testified in adult magistrate courts had additional trauma $[\mathrm{P}$ value $=0.831]$ unlike those who testified in juvenile courts $[\mathrm{P}$ value $=0.71]$.

When the researcher interviewed two groups of child victims of sexual abuse, about 70 per cent of those who appeared in court as child witnesses had behavioural problems such as fears, stress and depression compared to only 40 per cent of the child victims of sexual abuse who had not appeared as child witnesses in the courts of law. The researcher thus attributed these differences to the trauma of testifying in court.

\section{Removal or Separated from the Mother or Primary Caregiver}

The third research question about removal from the home, was the primary variable in the legal phase intervention. Removal from the home of a primary caregiver 
revealed that twenty-five children (46\%) who were removed from their homes because the family member was the perpetrator did not experience any additional trauma $[\mathrm{P}$ value $=0.021 \mathrm{NS}]$. Of the child witnesses who were removed from the mother or primary caregiver because of the abuse thirty-five per cent [35\%] of them sought support from someone other than their primary caregiver because of the failure of the mother to believe that the sexual abuse had taken place. Fortyeight per cent [48\%] of the children who were removed stated that the removal was helpful and twenty per cent (20\%) felt it had no effect on them. An interview with legal practitioners revealed that safety from the perpetrator was cited ninety per cent $(90 \%)$ of the time as the reason for removal was helpful.

\section{Figure 1: Multiple Interviews/Multifaceted Questioning}

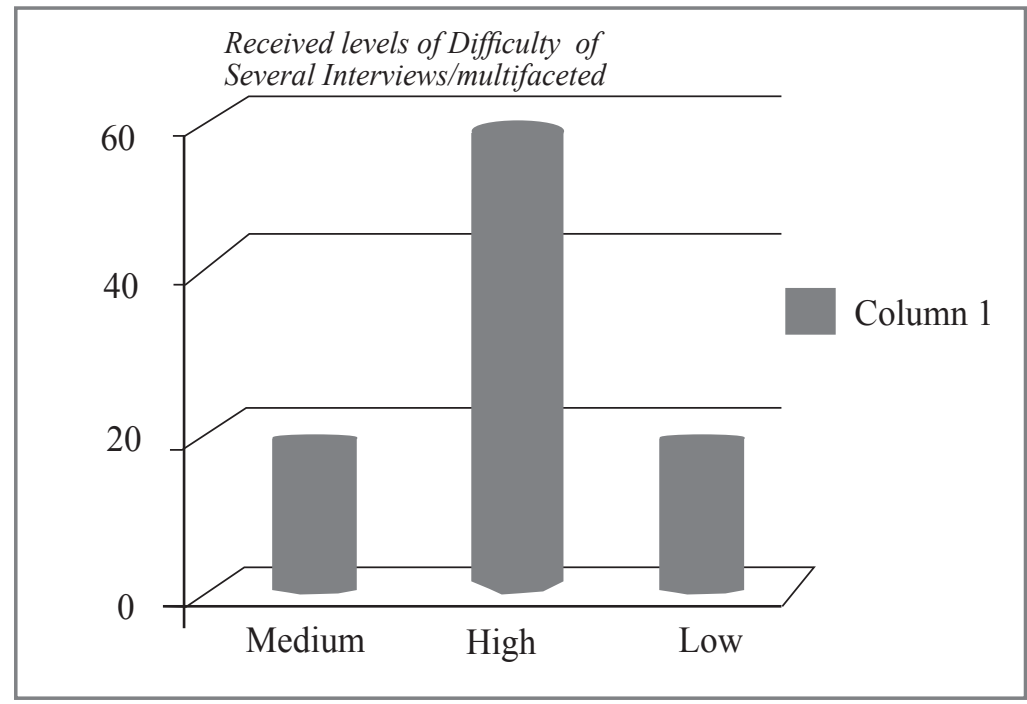

Source: Field Data, 2012

Over 50 per cent $(50 \%)$ of child witnesses found it stressful to go through several interviews and understand some of the questions because according to them they were too long.

A close analysis by the researcher of the questions asked by legal professionals to child witnesses revealed that they contained two or three (3) sub-questions thereby compelling the child to only answer the last part of the board question which she could remember. An example cited in this respect falls in the category of age-inappropriate vocabulary. For example, do you know how you came here and why you came? 'Such a Question is a compound loaded with two broad questions - how and why' In instances like this, children only tend to answer the last bit of the broad question. Below is an extract from the views of some social welfare officers who accompanied the children to cross examinations. 'I observed that when child witnesses were asked long questions about sexual abuse, their answers were not adequate'. 
Figure 2: Removal from the Mother or Primary Caregiver

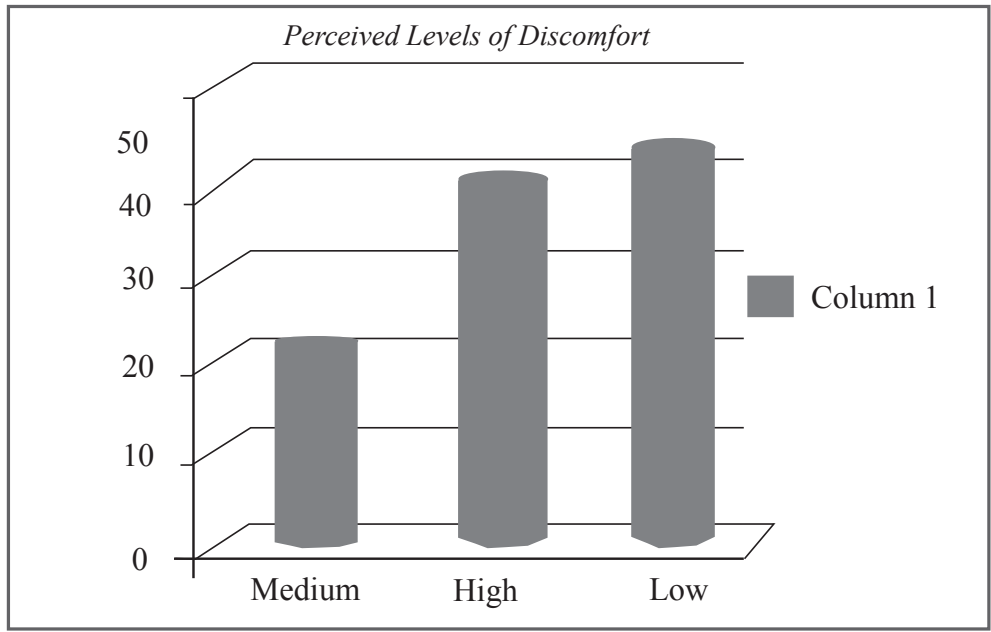

Source: Field Data, 2012

When those who were removed from their caregivers (home) were asked how they felt, 46 per cent of the children stated that they felt safe to be away from the perpetrator. However, 41 per cent of the children who were removed from home to a safer place reported high levels of discomfort to be separated from their primary caregivers because removal could have been made easier if legal professionals had taken time to listen to what they had to say about removal and prepare them better for this transition.

Another way of handling the situation had been to remove the perpetrator from his home by means of a court injunction.

\section{Credibility of Child Witness in Regular Adults Courts}

\section{Figure 3: Experience of Sexual Child Witnesses in Regular Adult Courts}

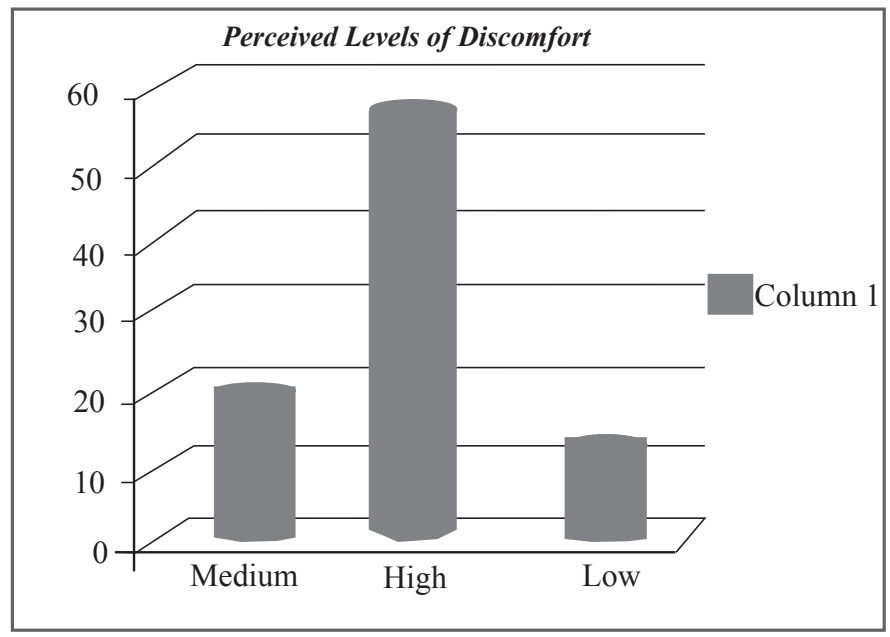


When asked how safe they felt in the adult magistrates courts, 60 per cent $(60 \%)$ of the child witnesses felt that they were scared. A deductive analysis of the perceived levels of discomfort indicated that an environment perceived to be less child-friendly led to anxiety which can negatively affect the trial. This showed that although cross examinations were designed to discredit the witnesses, it was necessary to adopt strategies that would safeguard children against being scared or feel unsafe when being cross-examined.

\section{B. Trust Between Sexually Abused Children and Professionals Attending to them}

\section{Figure 4: Trust Between Sexually Abused Children and Professionals Attending to them}

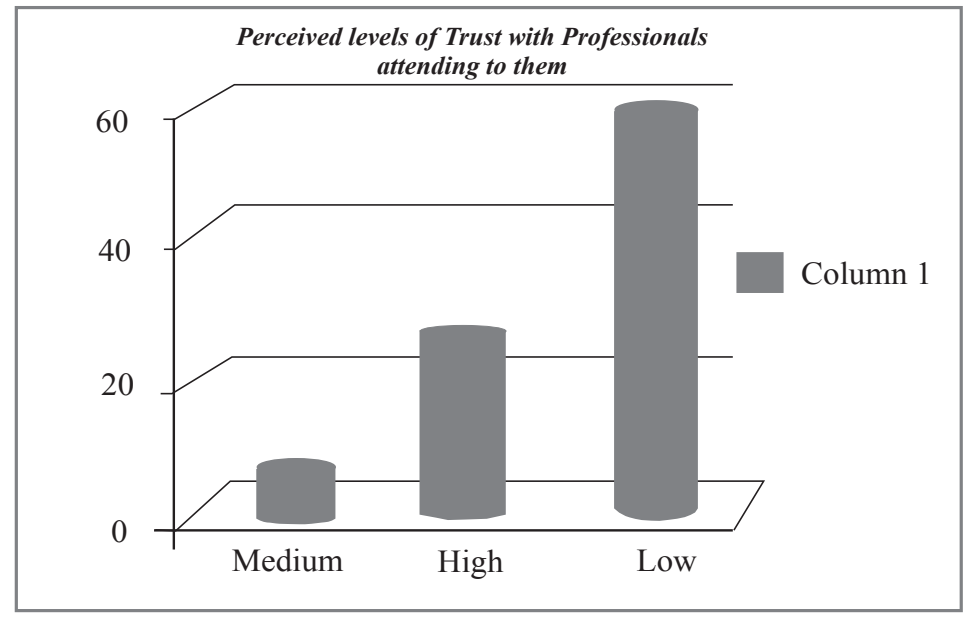

Source: Field Data, 2012

Sixty $(60 \%)$ per cent of the sexually abused child witnesses had low trust levels because of the misconception on the role played by judges, lawyers and prosecutors. When asked who they thought these people were, they thought that they were law enforcers who would take them to jail if they were not believed and this made them feel sad and scared.

\section{DISCUSSION OF RESULTS}

\section{Introduction}

This chapter discussed the results obtained in the study in the following sequence: Interventions of more than one investigatory interview or multifaceted questioning; testifying in regular criminal courts; being removed from the mother or primary caregiver; inability of professionals involved to establish trust as perceived by the child.

\section{Multiple Interviews}

The study indicated that there was an association between additional trauma levels and number of interviews. This result is in line with the findings of Goodman et al., (1988), that subjecting a child who has been sexually abused to multiple interviews and multifaceted questioning has numerous negative effects. For instance, when a 
child is asked to repeat the same story about what happened when he/she was abused, this experience can lead to additional distress or trauma. It can also be argued that a situation in which a child is compelled to repeat his/her story again and again makes the evidence begin to sound like a rehearsed version because of the acquisition of some of the terminologies of his/her interviewers. Consequently, this outcome gives the court an impression that the child has been coached.

\section{Multiple Questioning}

The study revealed that over 55 per cent of the child participants found it difficult to understand some of the questions because they were loaded with two broad subquestions embedded within one question. It was thus observed that in such instances, child witnesses of sexual abuse tended to only answer the last part of the broad question. This finding of the study is in agreement with findings of studies by Stevens and Berliner (1980), which showed that lack of adequate comprehension of what is being asked during the cross examination compromises to a large extent, the quality of response from the child witness. Explained differently, it is not just the use of court jargon that inhibits good comprehension of the question, but also the manner in which questions are asked. This shows that all professionals involved in child witnessing need to learn developmentally appropriate questions if ever they are going to improve the utility and quality of children's testimonies and at the same time reduce the chances of children getting traumatised by their court room experiences.

Children who are subjected to inappropriate questioning cannot communicate effectively what happened to them and what they observed. Multifaceted questioning can make the experiences of witnessing really upsetting for a child. Certain legal practitioners may claim that traumatic questioning is one way to get the truth, but multifaceted questioning can surely obscure the truth. This is so because children at this level have not yet developed the necessary language and reasoning skills to answer multifaceted questions meaningfully.

\section{Being Removed from the Mother or Primary Caregiver}

The finding of the study revealed that 48 per cent of the child witnesses who had been separated from their caregivers (home) felt safe to be away from the perpetrator while 76 per cent of the children who were removed from home to a safer place indicated that removal could have been made easier if professionals had talked to them more, listened to what they had to say about removal and prepared them better. This result is in agreement with findings of a study conducted by Sywtz (1995) and Goodman (1988) which revealed that generalised anxiety which is most often associated with fear of the perpetrator and the new place could lead to avoidance in child witnesses. Implications of this finding are that rather than remove the child from her home, perhaps it would be a better idea to remove the perpetrator from that home even if he/ she is on bail. 


\section{Credibility of Child Witness Testifying in Regular Adult Courts}

The findings have revealed that most children 60 per cent $(60 \%)$ of the child witnesses felt that they were scared of regular adult court. In other words, they perceived them to be less child-friendly. This explains reasons for their apprehensions and discomfort, which beyond reasonable doubt could have negatively affected the trial. This result is in agreement with the findings of Cashmore and Bussy (1990) which revealed that the child witnesses of sexual abuse were afraid of going to court because they would have to prove their own innocence in court, failure to which the defence would try to implicate them in the crime.

\section{Trust Between Sexually Abused Children and Professional Attending to them}

To establish whether or not inability of professionals involved to establish trust as perceived by the child increases trauma was one of the objectives in the study which was meant to determine whether there was an impact in the trust sexually abused children have in professionals attending to them and the children's trauma levels. The descriptive statistical analysis of the study revealed that it appears that children who had established trust with legal professionals dealing with their cases had a likelihood of significantly lower trauma scores than those that did not.

According to children, it is always bad people who go to court and so the child is scared that she can be put away in jail for whatever reasons. This inference is of great concern because children's perception of the court has such an important effect on the quality of the evidence. The reason it is important for legal practitioners to sensitively build rapport with the child is because they already have a predisposition of inability to trust following the sexually abuse.

\section{Data Analysis}

The qualitative data collected during Phase I of the main study was analysed through processing transcriptions of materials which were recorded. This material was further analysed using a strategy of coding and recursive observation. Emerging issues were then grouped into common themes and analysed thereafter so that divergent views were sought and reported.

The analysis of qualitative data was concentrated on meanings expressed through words and the analysis conducted through the use of conceptualisation. As Saunders et al. (2000: 381) observed that the nature of qualitative data has implications for both its collection and analysis. Hussy and Hussey (1997: 248) suggest that there are three related elements in the analysis of qualitative data. These are:

(1) Reducing the data and condensing the material in some systematic manner in order to make it more manageable,

(2) Structuring the data in terms of themes, patterns and interrelationships,

(3) De-textualising the data by converting extended texts into more manageable forms, such as summaries, charts, diagrams and illustrations. In the case of quantitative data, the research questions that certain system intervention 
strategies exacerbates trauma and stress in child sexual abuse was analysed in terms of person correlation levels of trauma and societal strategies.

\section{RESULTS}

The results have been presented according to the following themes:

1. Multiple interview/multifaceted questioning.

2. Testifying in adult magistrate courts.

3. Removal or separated from mother or primary caregiver.

4. Trust between sexually abused children and professionals attending to them.

5. Credibility of child witness in regular adult courts.

\section{Table 1: Corrections of Levels of Trauma and the Societal Interventions Strategies}

\begin{tabular}{|c|c|c|c|}
\hline $\begin{array}{l}\text { Mean Number of Interviews } \\
\text { in all the societal intervention } \\
\text { phases }\end{array}$ & $\begin{array}{l}\text { Mode of Number } \\
\text { of Interviews }\end{array}$ & Percentage & $\begin{array}{l}\text { Correlation between No. } \\
\text { of Interviews and trauma } \\
\text { scores }\end{array}$ \\
\hline $\mathbf{3}$ & $\mathbf{4}$ & $\mathbf{6 1 \%}$ & P value $\mathbf{0 . 0 1 3}$ \\
\hline
\end{tabular}

Source: Field Data, 2012

\section{The Level of Association Being 0.29}

\begin{tabular}{|c|l|l|}
\hline S/No. & Factors Correlated to Trauma Symptoms & Correlation coefficient \\
\hline 1. & Multiple interviews & $.878^{* *}$ \\
\hline 2. & Testifying in adult magistrate courts & $.831^{* *}$ \\
\hline 3. & Testifying in juvenile courts & $0.071 \mathrm{NS}$ \\
\hline 4. & $\begin{array}{l}\text { Removal or being separated from primary caregiver } \\
\text { who is a perpetrator }\end{array}$ & $.061 \mathrm{NS}$ \\
\hline 5. & Being subjected to more than three (3) interviews & $.878^{* *}$ \\
\hline 6. & $\begin{array}{l}10 \% \text { of children subjected to less than three }(3) \\
\text { interviews }\end{array}$ & $0.081 \mathrm{NS}$ \\
\hline 7. & Multiple Questioning & $.813^{* *}$ \\
\hline
\end{tabular}

$\mathrm{P}<0.01$ Significant $\mathrm{P}<0.05 \quad$ NS Not significant

Source: Field Data, 2012

\section{Multiple Interviews}

The mean number of investigatory interviews per child was three. The mode was four interviews with thirty children (55\%). Correlations were used to analyse the data for a number of interviews and trauma score. The correlation between the number of interviews and trauma scores yielded a P Value of .013 with the level of association being 0.29 which was significant.

Regarding multiple interviews, the present study revealed that being subjected to more than four interviews led to an experience of additional trauma in the child witnesses of sexual abuse ( $\mathrm{P}$ value $=0.08, \mathrm{NS})$. 


\section{E. Testifying in Adult Magistrate Courts}

During the legal intervention phase, thirty-four children testified in the juvenile court while twenty testified in the adult magistrate courts. The correlation between trauma and testifying in adult magistrate courts was 0.831 which is significant while that for juvenile courts was 0.071 which is not significant. The present study revealed that children who testified in adult magistrate courts had additional trauma $[\mathrm{P}$ value $=0.831]$ unlike those who testified in juvenile courts [P value $=0.71]$.

When the researcher interviewed two groups of child victims of sexual abuse, about 70 per cent of those who appeared in court as child witnesses had behavioural problems such as fears, stress and depression compared to only 40 per cent of the child victims of sexual abuse who had not appeared as child witnesses in the courts of law. The researcher thus attributed these differences to the trauma of testifying in court.

\section{F. Removal or Separated from the Mother or Primary Caregiver}

The third research question about removal from the home, was the primary variable in the legal phase intervention. Removal from the home of a primary caregiver revealed that twnty-five children $(46 \%)$ who were removed from their homes because the family member was the perpetrator did not experience any additional trauma $[\mathrm{P}$ value $=0.021 \mathrm{NS}]$. Of the child witnesses who were removed from the mother or primary caregiver because of the abuse 35 per cent (35\%) of them sought support from someone other than their primary caregiver because of the failure of the mother to believe that the sexual abuse had taken place. Forty-eight per cent (48\%) of the children who were removed stated that the removal was helpful and 20 per cent felt it had no effect on them. An interview with legal practitioners revealed that safety from the perpetrator was cited 90 per cent of the time as the reason for removal was helpful.

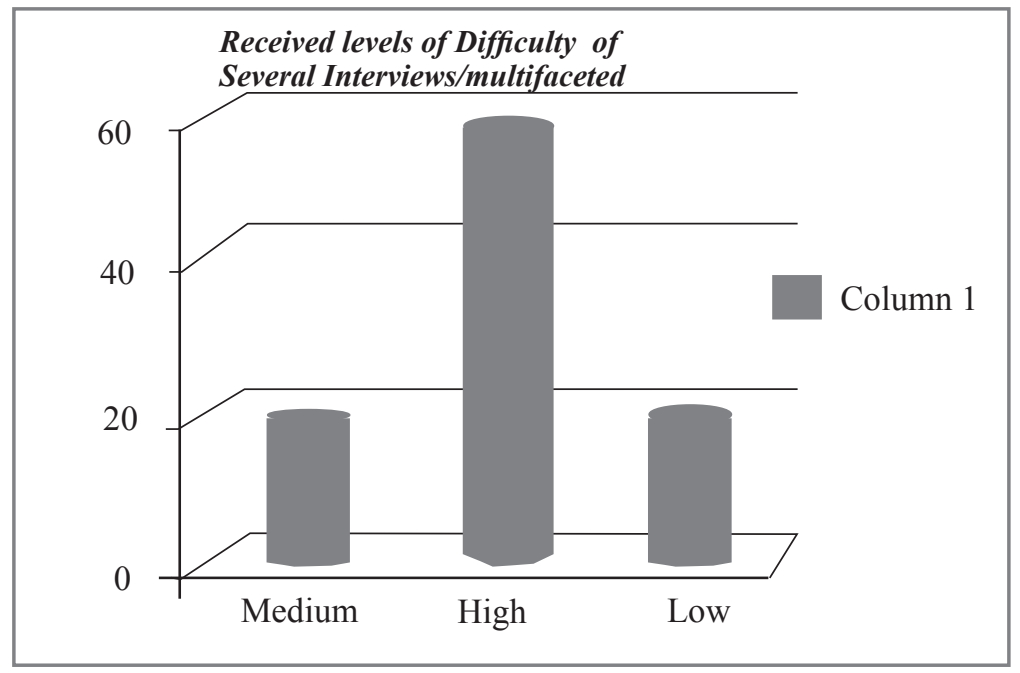

Source: Field Data, 2012 
Over 50 per cent $(50 \%)$ of child witnesses found it stressful to go through several interviews and understand some of the questions because according to them they were too long.

A close analysis by the researcher of the questions asked by legal professionals to child witnesses revealed that they contained two or three sub-questions thereby compelling the child to only answer the last part of the board question which she could remember. An example cited in this respect falls in the category of age-inappropriate vocabulary. For example, do you know how you came here and why you came? 'Such a Question is a compound loaded with two broad such questions - how and why.' In instances like this, children only tend to answer the last bit of the broad question. Below is an extract from the views of some social welfare officers who accompanied the children to cross examinations. 'I observed that when child witnesses were asked long questions about sexual abuse, their answers were not adequate'.

\section{Figure 2: Removal from the Mother or Primary Caregiver}

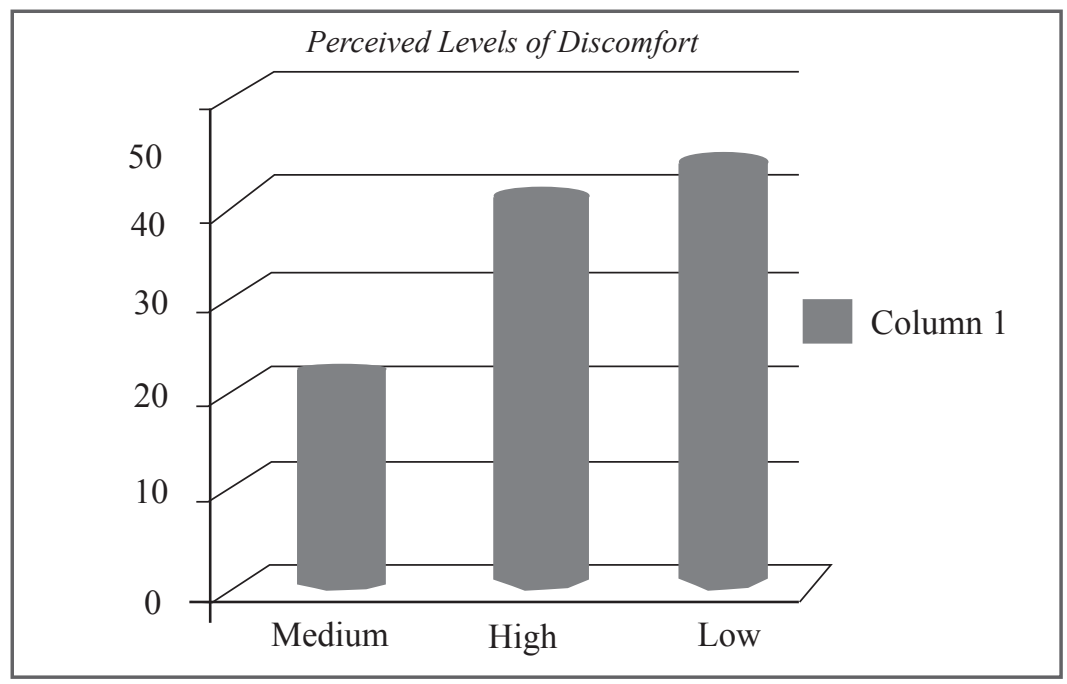

Source: Field Data, 2012

When those who were removed from their caregivers (home) were asked how they felt, 46 per cent of the children stated that they felt safe to be away from the perpetrator. However, 41 per cent of the children who were removed from home to a safer place reported high levels of discomfort to be separated from their primary caregivers because removal could have been made easier if legal professionals had taken time to listen to what they had to say about removal and prepare them better for this transition.

Another way of handling the situation had been to remove the perpetrator from his home by means of a court injunction. 


\section{Credibility of Child Witness in Regular Adults Courts}

Figure 3: Experience of Sexual Child Witnesses in Regular Adult Courts

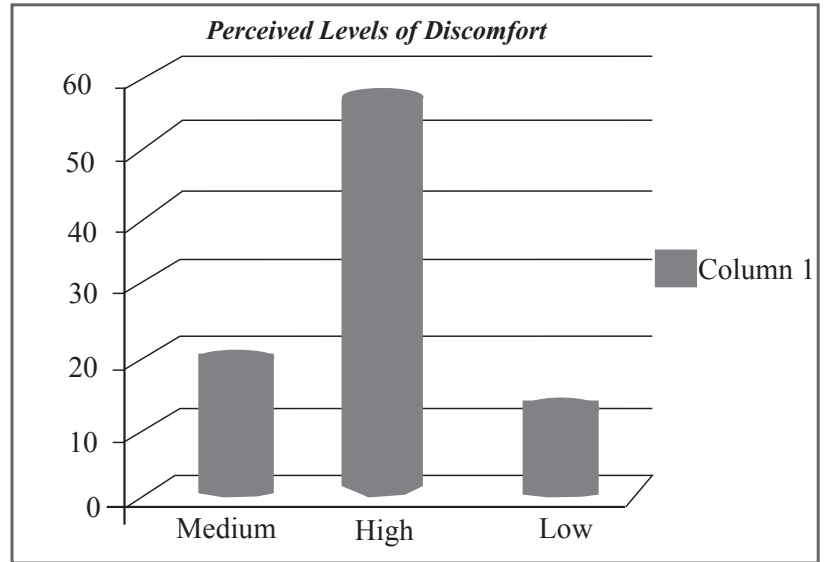

Source: Field Data, 2012

When asked how safe they felt in the adult magistrates courts, 60 per cent $(60 \%)$ of the child witnesses felt that they were scared. A deductive analysis of the perceived levels of discomfort indicated that an environment perceived to be less child-friendly led to anxiety which can negatively affect the trial. This showed that although cross examinations were designed to discredit the witnesses, it was necessary to adopt strategies that would safeguard children against being scared or feel unsafe when being cross-examined.

\section{B. Trust Between Sexually Abused Children and Professionals Attending to them}

Figure 4: Trust Between Sexually Abused Children and Professionals Attending to them

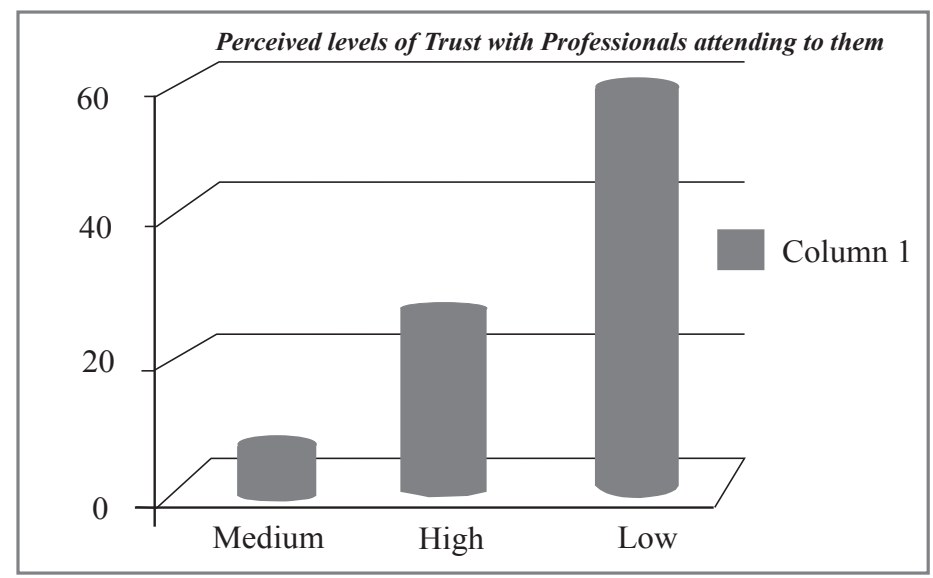

Source: Field Data, 2012

Sixty $(60 \%)$ per cent of the sexually abused child witnesses had low trust levels because of the misconception on the role played by judges, lawyers and prosecutors. When asked who they thought these people were, they thought that they were law enforcers who would take them to jail if they were not believed and this made them feel sad and scared. 


\section{DISCUSSION}

The study found that most of the participants who were sexually abused were abused by their family members $(n=39 ; 44.8 \%)$. This means that most of the cases were incestuous in nature. This finding is also documented by World Health Organisation (2002), that the vast majority of child sexual abusers were usually people that a child knew and trusted. Family members are the abusers in most of the cases because they have adequate information about the victims (HRW, 2002; YWCA, 1999).

It was also found that most of the victims did not disclose their sexual experiences to anyone $(n=59 ; 75.6 \%)$. This could have been the case because children who are subjected sexual abuse are often afraid to report due to shame and fear of stigmatisation of themselves and their families (Global Action for Children, 2005). Secondly, in most cases, abusers use direct threats of physical harm to children or their families. HRW (2002) and Young Women Christian Association (1999) found that the disclosure of sexual abuse cases either by the victims themselves or their families is a challenge most of the time. This is because most of the abusers are related to the children and may even be their parents or guardians.

Parental absence was discovered to be the most powerful risk factor for child sexual abuse $(n=63 ; 73.3 \%)$. Specifically, maternal employment and illness of one or both parents were associated greatly to increased likelihood of a sexual abuse experience. The explanation is that parental absence leads to the creation of certain environments that are conducive for child sexual abuse. Children are at increased risk when their parents' suspension is absent to protect them from exploitative adults (Finkelhor \& Baron, 1986). Parental absence can reduce parental opportunities to meet children's emotional needs and children with poor emotional adjustment, in high need for attention and affection are more likely to respond to other attentive and available adults (Finkelhor \& Baron, 1986; Gruber \& Jones, 1983; Benedict \& Zautra, 1993).

Physical discipline as a risk factor was reported by $(n=59 ; 68.7 \%)$ of the participants. According to the World Health Organisation (2002), children who are physically abused develop low self-esteem and low self-esteem is one of the characteristics of children and adolescents who are vulnerable to sexual abuse (Dam, 2000). Therefore, when a perpetrator notices a child with low self-esteem, they become targets for abuse.

Alcohol intake by a parent or guardian increases the chances of a child being sexually abused (Ferguson, Lynsky \& Horwood, 1996). The explanation is that children whose parents or guardians take alcohol and/or other drugs lack supervision abilities because their parents or guardians are usually not there to ensure that their welfare is taken care of. In addition, such parents or guardians may even themselves abuse their own children when they are under the influence of alcohol (Lehrer, Lehrer, Lehrer \& Oyarzun, 2007). Despite this being true, other research findings such as the one done by Finkelhor, Moore, Hamby \& Straus (1997) show that there is no association between child sexual abuse and having a parent or guardian who takes alcohol. In spite of these variations in the findings, results collected in this study show that alcoholism in a family is a risk factor for child sexual abuse. Therefore, the hypothesis that alcohol intake by a parent or guardian is not a significant risk factor for 
child sexual abuse has been rejected. An alternative hypothesis that alcohol intake by a parent or guardian is a significant risk factor for child sexual abuse has been adopted.

A poor parent-child relationship as a risk factor for child sexual abuse was found in 23.7 per cent of the victims $(n=20)$. Poor parent-child relationship had a similar score with parental conflict $(\mathrm{n}=19 ; 22.4 \%)$. The connection between the two risk factors is that, a child who witnesses parental conflict is likely to have impaired attachment with either or both parents. This is consistent with the findings of Ferguson et al. (1996), who asserts that marital conflict is a risk factor for child sexual abuse.

The presence of a step-parent, especially a step-father, seems to increase the risk for sexual abuse. In this study, $(n=13)$ participants $(13.1 \%)$, lived in a home where there was a step-parent. The explanation is that a step-parent, especially a father, could he himself be an abuser. Madu and Peltzer (2000) found step parenting to be a risk factor for child sexual abuse.

Most of the participants, $(n=56,69 \%)$, reported that they were not aware that certain behaviours exhibited by their abusers would result into sexual abuse. This is because sexual abuse perpetrators assimilate themselves into a child's life and create a trusting relationship with the child and sometimes with the child's family. Therefore, due to the trusting relationship that is created, a child may fail to recognise that the grooming tactics are a means to get to them. Furthermore, many abusers go out of their way to be charming, nice and helpful so that they divert the attention of the child away from their deeper motive. Sometimes, children's young age may also prevent them from being able to know that certain adult behaviours towards them may result into sexual abuse (Sanderson, 2004).

\section{CONCLUSION}

The study indicated that certain types of legal societal system interventions such as multiple questioning, more than three interviews, child-mother or caregiver separation, inadequate trust during the investigation and the use of jargon language through multifaceted questioning in court further traumatise sexually abused children.

\section{RECOMMENDATIONS}

1. Based on the findings of this study pertaining to the legal societal interventions in matters relating to child sexual abuse, it is recommended that further studies be carried out in order to understand better this area of possible concern because insufficient time to do a longitudinal study was the major limitation of the study observed.

2. It should be acknowledged that it is common that sexual abuse cases involve repeated abuse perpetrated someone close to the child. Because the material used in the study is rather unique, the researcher recommends that one needs to be cautious about generalising these results to a broader group of sexually abused children. On the other hand, children's unwillingness to report, or disclose sexual abuse is probably more evident in intrafamillial than extrafamillial cases. 
For example, due to loyalty conflict and fear of negative consequences for the family and life situation, this provides a complimentary contribution indicating that it maybe even be more difficult to report sexual abuse than has previously been suggested when the perpetrator is total stranger.

3. In order to overcome complaining barriers and be able to report, the researcher recommends that the child must be made to feel comfortable in the interview situation and trust the interviewers. Furthermore, the interviewers must have patience and time to listen to the child. Consequently, considerable focus during the interview must be put on establishing rapport with the child.

Since it was established that the most frightening experience in testifying was the presence of the perpetrator in the court room, the researcher recommend that more research is required to validate the effectiveness of having the child witness to be cross-examined in a separate room via tele-conferencing facilities or other means of media as long as they cannot see the perpetrator as they are being cross-examined.

\section{REFERENCES}

Berliner, L. and Barbieri, M.K. Barbieri, M.K. (1984), 'The Testimony of the Child Victim of Sexual Assault', Journal of Social Issues, 40 (2): 125.

Cashmore and Bussey (1990), 'Children's Conceptions of the Witness Role'. In Spencer, J.R. and Flin. R.H. (Eds) (1993), The Evidence of Children: The Law and Psychology. London: Blackstone Press.

Finkehor and Browne (1985), The Traumatic Impact of Child Sexual Abuse: A Conceptualisation.

Finkelhor, D. (1994), Current Information on the Scope and Nature of Child Sexual Abuse: The Future of Children, Vol. 75, pp. 31- 53.

Keeney et al. (1992), 'the Court Prep Group: A Vital Part of the Court Process'. In Dent and Flin (Eds) Children as Witnesses, 210.

Keeney et al. (1992), 'the Prep Group: A Vital Part of the Court Process'. In Dent and Flin (Eds), Children as Witnesses, 201.

National Guidelines for the Multidisciplinary Management of Survivors of Sexual and Gender Based Violence in Zambia, 2010.

Sgroi, S., Blick, L. and Porter, F. (1982), 'A Conceptual Framework for Child Sexual Abuse'. In S. Sgroi (Ed.), Handbook of Clinical Intervention in Child Sexual Abuse. Lexington Books.

Tedesco, J.F. and Schnell, S.V. (1987), 'Children's Reactions to Sex Abuse Investigations and Ligations', Child Abuse and Neglect, 11: 267-272. 